\title{
El interés por el paisaje en la política turística española de la segunda mitad del siglo xx (1951-1978)*
}

\section{The interest in the landscape in the Spanish tourism policy for the second half of the 20th century (1951-1978)}

\author{
Dolores Brandis García ${ }^{1}$
}

\begin{abstract}
RESUMEN
A partir de la segunda mitad de siglo xx y hasta la creación del Estado de las Autonomías la política turística aborda el conjunto del país como marco donde aplicar medidas para explotar los territorios con mejores recursos, entre ellos el paisaje, y conseguir aumentar la llegada de visitantes. A la vista de la acelerada agresión que sufren las áreas costeras y el desigual deterioro que manifiestan los paisajes del interior peninsular, se pasa a abordar en qué medida contribuyó a estos resultados la consideración y el tratamiento dado al paisaje por la política turística. El análisis se apoya en documentación oficial, bibliografía contemporánea y en la que desde la perspectiva actual aborda la política turística del periodo.
\end{abstract}

PAlabras Clave: paisajes; política turística; desarrollo turístico; franquismo; España.

\section{Abstract}

The Spanish tourism policy, aiming at exploiting the territories with better resources (landscape included) for a growing number of visitors, was implemented across the country as a whole since the second half of the $20^{\text {th }}$ century until the establishment of the State of Autonomies. This paper intends to assess the relation between the role of landscape in this national tourism policy and the current degradation of the Spanish

\footnotetext{
* Este trabajo se ha realizado dentro del Proyecto de Investigación "La valoración patrimonial e identitaria del paisaje en España (1875-2010): claves geográficas, culturales y políticas", CSO2012, financiado por el Ministerio de Economía y Competitividad.

${ }^{1}$ Universidad Complutense de Madrid, dbrandis@ghis.ucm.es.
} 
coastline compared to the inland. Data sources were official documents as well as contemporary bibliography.

KEY WORDS: landscape; tourism policy; tourism development; Francoism; Spain.

\section{INTRODUCCIÓN}

A partir de la segunda mitad de siglo xx y hasta el Estado de las Autonomías el Gobierno de Franco aborda una política turística, más abierta al exterior y liberalizadora en el interior, que contempla el conjunto del país como marco donde aplicar las medidas necesarias con el fin de explotar los territorios con mejores recursos para conseguir aumentar la llegada de visitantes. El propósito de este trabajo es dilucidar si existió un desigual tratamiento en la política turística respecto al territorio y el paisaje a la vista de los resultados que desembocaron, por un lado en la progresiva agresión hacia los paisajes costeros, sobre los que presionaban los intereses de la creciente demanda turística extranjera y nacional, que quedaron a merced de la especulación y revalorización mercantil y, por otro, en un desigual deterioro de los paisajes del interior, debido a la apatía de la promoción privada a invertir en espacios escasamente solicitados por el turismo extranjero.

La información recabada para abordar la política turística y sus impactos en el paisaje contempla tres niveles. El primero se refiere a la documentación oficial custodiada en el actual Ministerio de Industria, Energía y Turismo y, en menor medida, en el Archivo General de la Administración, amén de todo el aparato legislativo recogido en el Boletín Oficial del Estado. El segundo lo conforma una abundante bibliografía historiográfica, económica, turística y geográfica que desde mediados de los años setenta revisa parte de la anterior documentación, da cuenta de sus contenidos y presupuestos e incorpora, en algunos casos, reflexiones críticas. El tercer nivel recoge opiniones procedentes de distintos sectores públicos y privados, contemporáneas a la política turística del periodo estudiado, que venían a cuestionar los presupuestos de la misma, evaluaban su grado de efectividad o denunciaban los impactos negativos en su puesta en práctica.

\section{LA FALTA DE CONTROL POlítico y LAS AGRESIONES AL PAISAJE DE LOS PRIMEROS AÑOS}

En la reestructuración ministerial de 1951 se crea el Ministerio de Información y Turismo, con Arias Salgado a la cabeza, con el objetivo fundamental de 
incrementar el número de visitantes extranjeros y la capacidad de alojamientos. Pero no será del Ministerio quien elabore el primer Estudio para un Plan General de Turismo, sino la Presidencia del Gobierno a través de Secretaría General para la Ordenación Económico-Social. El estudio sentará las bases del Primer Proyecto del Plan Nacional de Turismo para ordenar la llegada de turistas y crear un instrumento específico de planificación, las denominadas zonas de interés turístico, y unas previsiones normativas. Estos presupuestos se incorporan al Borrador del Proyecto de Ley sobre Protección y Fomento de Zonas de Interés Turístico (Velasco, 2004).

En 1953 se aprueba el Plan Nacional de Turismo, en este caso preparado por el Ministerio y la Secretaría General para la Ordenación Económico y Social (Velasco, 2008), que establece un plan global de actuaciones para atraer a dos millones de turistas anuales, regular el sector y ordenar la oferta turística según su tipo de interés: histórico-artístico, folklore, descanso y recreo, deportivo, cultural y negocios. En paralelo continúa trabajando la Secretaría General en el Anteproyecto de Ley sobre Protección y Fomento de Zonas de Interés Turístico que concluye en 1955, creándose una Comisión Interministerial para guiar y coordinar las actuaciones de las distintas administraciones en la promoción turística de los espacios con mejores recursos. Y será también esta Secretaría la que elaborará los primeros planes de promoción y desarrollo turístico, focalizados en las zonas litorales (Costas del Sol, Brava y Dorada y los archipiélagos balear y canario) y de montaña (Sierra Nevada, Pirineos y Navacerrada). Por su parte, el Ministerio se encargará de mantener las Rutas Nacionales de Turismo, las antiguas «Rutas de Guerra», y declarar otras más a través de un organismo autónomo creado en 1958, la Administración Turística Española.

Poca fue la efectividad de todas estas medidas aparecidas en tan sólo cinco años. La Ley sobre Protección y Fomento de Zonas de Interés Turístico no pasó de anteproyecto y la Comisión Interministerial falló en la coordinación y fue incapaz de poner en ejecución las políticas del Plan Nacional (Vallejo, 2014). Los planes de promoción y desarrollo turístico fueron estudios retóricos de nula operatividad ante la falta de referencia a una legislación específica (Barrado y Galiana, 2006). Se ponía en evidencia la escasa relevancia que tenía el Ministerio en la política turística, por lo que su operatividad fue prácticamente inexistente, y no intervino en ningún sentido, ni para fomentar ni para controlar, pues ni siquiera puso en marcha nuevas rutas turísticas y tampoco se eleva al Consejo de Ministros el Anteproyecto de Bases para un nuevo Plan de Fomento y Promoción de Turismo que él mismo impulsaba (Velasco, 2004). 
Fueron los territorios costeros y de alta montaña los que desde el primer momento merecieron la mayor atención política para su promoción y desarrollo turístico. Y aunque las iniciativas no llegasen a hacerse efectivas, sirvieron de espita para movilizar a la iniciativa privada. El resultado de la falta de control político fue la de una oferta desarrollada en un ambiente de libertad total para atender a una demanda que superó todas las previsiones. Aparecen núcleos turísticos promovidos por intereses privados, en conjunción con los ayuntamientos, nada respetuosos con el paisaje a lo largo de las costas mediterráneas y los archipiélagos. De esta realidad no es ajeno el Ministerio al manifestar que «Los altos precios especulativos sirven de base moral para forzar una densidad de edificación inadecuada y surgen así esas constelaciones de rascacielos que junto a las mejores playas españolas hacen generalmente menosprecio de bellezas preexistentes, reducen y modifican el campo visual de otros terrenos interiores, que reciben, de modo indirecto, los efectos de una depreciación indebida y disminuyen la posible calidad de toda una zona turística en un proceso continuado, en el que la culpabilidad final se diluye entre administradores y administrados» (Pack, 2009: 163).

\section{LA ACELERADA DEGRADACIÓN DE LOS PAISAJES COSTEROS}

A partir de 1959 la política turística del Ministerio se enmarca de lleno en el Plan de Estabilización Económica y Social del Gobierno, cuyo antecedente es el memorándum de ordenación económica remitido un año antes al Fondo Monetario Internacional, con el fin de alinear la economía española con los países del mundo occidental. En el informe se explicitan los factores favorables para fomentar el turismo exterior en el país: su clima soleado y agradable, la existencia de muchas playas y las atracciones históricas y culturales. Y será el Informe sobre la Economía Española de 1962, del Banco Internacional de Reconstrucción y Fomento, el que recomiende al Gobierno disponer de una estructura apropiada para favorecer la intervención de la iniciativa privada, una vez eliminados los límites a la participación del capital extranjero, siendo para ello necesario situar al turismo en un lugar más preeminente dentro de la Administración. La sugerencia no se hace esperar. Ese mismo año el Gobierno coloca a Manuel Fraga a la cabeza del Ministerio y lo convierte en el más influyente detrás de Gobernación.

La política turística del equipo de Fraga tendrá como objetivo prioritario conseguir aumentar el número de turistas, creciendo cuanto más mejor, pues el país necesita divisas y el turismo las puede proporcionar. Inmediatamente 
se dicta la Ley sobre competencias en materia turística que faculta al Ministerio a «la ordenación y vigilancia de toda clase de actividades turísticas, así como también al directo ejercicio de éstas en defecto o para estímulo y fomento de la iniciativa privada» y «la ordenación y coordinación del turismo» (Ley 48/1963: 10730). Para ello se crean la Subsecretaría de Turismo y dos Direcciones Generales: la de Promoción del Turismo, encargada de la propaganda y fomento del turismo, y la de Empresas y Actividades Turísticas para regular al sector privado.

La Subsecretaría de Turismo empieza en 1962 a elaborar las bases de un nuevo Plan Nacional de Turismo. Ante la necesidad de conocer con detalle los recursos turísticos del país, con vistas a planear su propaganda y puesta en valor, determina celebrar asambleas provinciales que aporten información de sus recursos y aspiraciones turísticas. Asimismo, y ante los problemas de congestión en determinadas zonas propone la elaboración de una ley que ordene el desarrollo y explotación de los atractivos turísticos. La ley, que ya estaba preparada aunque aparcada por la desconfianza que despertaba en otros ministerios, especialmente en Vivienda, se aprueba el 28 de diciembre de 1963 con el nombre de Ley de Centros y Zonas de Interés Turístico Nacional, y lo hará el mismo día en que se aprueba el I Plan de Desarrollo Económico y Social, con el que muestra una clara correspondencia (Jaimez, 2004).

El I Plan de Desarrollo sostiene que la administración no puede limitarse a la mera función de vigilancia y ordenación de las iniciativas turísticas privadas, sino que ha de apoyarlas y suplir su falta en caso necesario. Para aumentar los visitantes se deberán emprender acciones orientadas a: ampliar y ordenar espacialmente la oferta; planificar las zonas turísticas; obtener suelo para ponerlo a disposición de la iniciativa privada en zonas no explotadas; y aumentar las facilidades para las inversiones extranjeras.

La Ley de Centros y Zonas, conocida como «Ley Fraga», retoma el Anteproyecto de 1955 del que elimina el término «protección» en el título y no muestra en su desarrollo ninguna preocupación por el deterioro del paisaje, ya evidente en muchos espacios. Sólo alude a fenómenos de saturación en determinadas zonas y sostiene que existen otras dotadas por la naturaleza de suficientes atractivos para convertirse en turísticas. Enuncia como objeto de la ley «la ordenación turística del territorio nacional por medio de la planificación y desarrollo de Centros y Zonas de Interés Turístico» (Ley 197/1963: 18227). Y su misión, además, será la de facilitar la actuación de la iniciativa privada a través de beneficios económicos y fiscales; conseguir suelo por excepcional utilidad pública; y determinar los derechos de uso y disfrute de los dominios públicos del Estado y de las Corporaciones locales. 
Para la aplicación de la Ley se diseñan las figuras de Centro y Zona. La primera como un área delimitada de territorio con condiciones especiales para la atracción y retención del turismo. La segunda se correspondería con un espacio geográfico donde existiesen ya dos o más centros declarados. Podían solicitar su declaración el Ministerio de Información y Turismo, el Gobernador, las Diputaciones Provinciales, los Ayuntamientos, los Organismos del Movimiento y las Entidades Sindicales, añadiéndose en el caso de los centros los promotores de obras, instalaciones o servicios turísticos. Para presentar las solicitudes, el centro debía tener aprobados un Plan de Promoción Turística y un Plan de Ordenación Urbana, y la zona contar con un Plan de Ordenación Territorial y Urbana. Era el Ministerio el que aprobaba el Plan de Promoción de los centros y dejaba al Consejo de Ministros el de los Planes de Ordenación Urbana de ambos y la declaración final de Interés Turístico Nacional (Calderón, 2001).

A juicio de Fraga la ley nace mutilada al mantener el Gobierno la autoridad última para aprobar las solicitudes de declaración, y porque éstas debían acreditar el respaldo de las autoridades municipales, provinciales y sindicales. Además, la capacidad del Ministerio se verá también disminuida en el Reglamento de la ley de 1964, al dejar claro que el objetivo de fomento prima sobre el de ordenación del territorio. Esto recortaba aún más el papel directo que Fraga pretendía, pues limitaba su función a la de favorecer la inversión privada con beneficios económicos y fiscales (Serrano, 1965). Pero hay más, pues ese mismo año la Comisión Interministerial de Turismo reconocerá que la ordenación y planificación del turismo concierne a la política general del Gobierno, y el Ministerio del Interior dará más autoridad a los ayuntamientos a través de la Ley de Régimen Local.

Será el Reglamento de la Ley de Centros y Zonas el que entre en consideraciones paisajísticas. Especifica que la declaración irá orientada al fomento y creación de nuevos centros «en aquellos lugares que por sus especiales circunstancias tengan atractivos bastantes para su explotación turística [...] fijándose normas específicas para que las construcciones armonicen con el paisaje y tradiciones artísticas del lugar» y amplía los beneficios de la ley a los complejos turísticos ya existentes al objeto de que «mediante la declaración de interés turístico nacional, se les pueda otorgar la protección adecuada para la conservación y mejora de sus valores naturales» (Decreto 4297/1964: 838).

En paralelo se celebra la I Asamblea Nacional de Turismo como foro de la genuina representación de los intereses turísticos públicos y privados (Asamblea, 1964). En ella el ministro Fraga da cuenta del incremento de los visitantes extranjeros, que de poco más de un millón en 1951 han pasado en 1963 a casi once millones. Todas las provincias costeras ofrecen sus playas y las que 
cuentan con alta montaña su aptitud para el deporte de la nieve. Y se aportan otros recursos naturales del interior peninsular. Se trata de los espacios protegidos por su potencial paisajístico, los embalses y riberas de ríos para el baño y la pesca, y la media montaña para la caza. Los recursos histórico-artísticos interesan menos, pues los viajes culturales no parecen tener atractivo para el turista extranjero, tal y como señala el historiador Nazario González en 1964².

En el informe final de la Asamblea queda claro el interés del Ministerio en favorecer el turismo de sol y playa:

Los Intereses de la Economía Nacional tienen prioridad sobre los de carácter local, y en consecuencia, la actuación sobre las zonas de mayor atractivo para el turismo extranjero debe ser el objeto inmediato preferente, sin excluir la atención, en menor escala, hacia las zonas de alto interés para el turismo del interior [...] Corresponde a la iniciativa privada la mayor inversión económica de las actuaciones; por tanto, no pueden otorgarse declaraciones de interés turístico nacional en aquellas zonas en las que no existe ese impulso del capital privado (Asamblea, 1964: 132).

La Ley de Centros y Zonas dará lugar a enfrentamientos dentro del Gobierno. Vivienda le imputan invadir sus competencias en materia de ordenación del territorio (González-Berenguer, 1969) e insiste en la primacía de la Ley del Suelo de 1956 a través de la figura del Plan Especial para «la ordenación de ciudades artísticas, protección del paisaje y de las vías de comunicación, conservación del medio natural en determinados lugares, saneamiento de poblaciones y a cualquiera otras finalidades análogas» (Ley, 1956: 3111). Y eran previsibles más problemas de competencias en los territorios declarados de interés turístico, a cuyo interés se subordinaban todos los aprovechamientos de los bienes de dominio público ${ }^{3}$ (Serrano, 1965).

La puesta en valor turístico de los espacios costeros acarreó conflictos, especialmente en la zona marítimo-terrestre, en donde tenían competencias muchos ministerios (Serrano, 1966). Y aunque en el proyecto presentado en las Cortes no se reconocía la posibilidad de enclaves de propiedad privada, en la aprobación definitiva se introdujo «sin perjuicio de los derechos legalmente adquiridos», con lo que expresamente se venían a reconocer los citados encla-

2 En el artículo "Reflejos del turismo español en 1964", Razón y Fe, 170, sostiene que «el francés que ha visitado una vez Ávila no vuelve a ella. Si vuelve será como inquilino de los apartamentos de Tossa de Mar» (Sánchez, 2001: 215).

3 También autorizaba la reserva de territorios para su explotación turística, con independencia de sus mayores posibilidades de otra naturaleza, de forma que de existir industrias deberán efectuar las correcciones precisas a fin de acomodarse en su funcionamiento al interés turístico, pudiendo llegarse, de no ser posible, a la expropiación forzosa. 
ves privados (Zaragoza, 1999). En este sentido, Agricultura se opondrá en 1965 a la compra de terreno baldío para la promoción turística, y Hacienda pedirá en 1967 al Gobierno que declare la jurisdicción de los ayuntamientos sobre la totalidad de su territorio, incluyendo las zonas de costa y playas de interés turístico (Pack, 2009). Estas situaciones las venían denunciando desde hacía tiempo arquitectos e ingenieros. Insisten en que la Ley de Centros y Zonas no evita errores similares a los cometidos hasta entonces (Bosch, 1966) y denuncian que se han incrementado. Los centros, cuya localización la decidía la iniciativa privada, eran sobre todo enclaves turísticos con deficiencias en infraestructuras, playas sucias, extracciones de arenas fraudulentas y desagües de saneamientos en las zona de baños (Sanz, 1966).

Para solventar estos conflictos se recurre a una serie de medidas contempladas en el II Plan de Desarrollo de 1968. Así, la Jefatura del Estado aprueba la Ley de Costas pues «la abundante legislación dispersa y fragmentaria -más de un centenar de disposiciones, de las cuales una docena de rango legislativo-, en contradicción patente unas con otras, impone una regulación armónica y uniforme de la zona marítimo-terrestre» (Ley 28/1969: 6360) y establece que se precisará el informe favorable de Turismo cuando las obras, concesiones y autorizaciones, cualquiera que sea el ministerio que las realice u otorgue, afecten a zonas y centros declarados de interés turístico. También aprueba la Ley sobre Puertos Deportivos (Ley 55/1969) y fija en un año la elaboración de un plan de promoción. Por su parte Turismo propicia la Orden sobre Determinación de Zonas y Rutas Turísticas «a efectos de la planificación y proyección de la actuación administrativa en problemas relacionados con la materia turística» (Orden, 9/03/1971: 4469), estableciendo nueve zonas de las que seis recaen en territorios del litoral ${ }^{4}$.

Desde luego que hubo esmero oficial en publicitar el turismo costero en las campañas orientadas al exterior. Si en 1962 se manifiesta que «En estos últimos años, en España la mayor parte del esfuerzo realizado se ha hecho en base al clima, playas, sol y agua, folclore andaluz, y otros motivos que, aunque continúan teniendo efectividad y vigencia, han ido convirtiéndose en tópicos. Interesa ahora cambiar la faz que España presenta turísticamente al mundo» (Pack, 1969: 230), en la campaña «25 Años de Paz», diseñada por Fraga y difundida a lo largo de 1964, se decanta claramente hacia el turismo de sol y playa: «El tu-

\footnotetext{
${ }^{4}$ Las zonas eran: Costa Brava y Costa Dorada; Costa del Azahar y Costa Blanca; Costa del Sol y Costa de la Luz; Cornisa Cantábrica y Rías Gallegas; Pirenaica; Baleares; Islas Canarias; Madrid y su entorno monumental y artístico; Lagos de Castilla.
}

Estudios Geográficos, Vol. LXXVII, 281, pp. 391-414, julio-diciembre 2016 ISSN: 0014-1496, eISSN: 1988-8546, doi: 10.3989/estgeogr.201612 
rismo es un fenómeno nuevo porque en su forma actual es esencialmente distinto del turismo que conocieron nuestros abuelos; es un fenómeno de masas [...] el momento actual ha dado valor económico a circunstancias geográficas y climatológicas, a través del turismo. Las dos primeras son circunstancias naturales. Si se nos pidiera un slogan podríamos decir: "El sol español a las puertas de Europa" $»^{5}$ (Pack, 2009: 217). Y en la guía «España para usted», con una tirada de once millones de ejemplares en nueve idiomas, se aconseja visitar sobre todo las costas (Subsecretaría de Turismo, 1964). También se impone el eslogan «Spain is different» en los carteles de promoción, que será sustituido en los años setenta por el de «España, un lujo a su alcance».

El diagnóstico del estado de los territorios turísticos que realiza el III Plan de Desarrollo Económico y Social en 1972 no puede ocultar que gran parte de los problemas no se han resuelto, y muchos se han agudizado. Esto, a pesar de que para controlar la situación deficiente de muchos centros se hubiese dictado en 1970 el Decreto de Requisitos mínimos de infraestructuras y dotaciones en Zonas y Centros de Interés Turístico Nacional (Decreto 3787/1970). Se habían privatizado playas y zonas marítimo-terrestres, y al calor de los Centros se adosaban urbanizaciones turísticas y de segunda residencia que se adentraban cada vez más en los territorios del interior, provocando fricciones con los usos agrarios y naturales, y se habían cercado grandes espacios atentando gravemente sobre antiguas servidumbres de paso. Al primar el negocio inmobiliario la especulación del suelo se hacía imparable y las urbanizaciones turísticas crecían exponencialmente ${ }^{6}$, llegando a situaciones alarmantes en los espacios más demandados ${ }^{7}$. Las urbanizaciones de la costa habían proliferado sin atender las normas legales ${ }^{8} \mathrm{y}$, en ocasiones, con el beneplácito de los pro-

${ }^{5}$ Este tipo de mensajes se fueron haciendo cada vez más habituales a partir de la llegada de Fraga al Ministerio. En 1962 uno de cada 50 documentales del NO-DO se basaban en el turismo y entre 1963 y 1969 fueron uno de cada once y, a menudo, uno a la semana durante el verano (Pack, 2009).

${ }^{6}$ En un estudio sobre 28 provincias que suman más de 700.000 has., las afectadas por las urbanizaciones turísticas eran 225.000 y en las que el precio de los terrenos entre 1950 y 1966 pasó de un índice 100 a 3.000 en el suelo urbanizado, a 2.000 en suelo adquirido para la urbanización y a 1.000 en suelo favorable para la misma (Arespacochaga, 1966)

${ }^{7}$ Desde finales de los años sesenta se multiplicó por dos la superficie promovida, legalizada y especulada en la Costa del Sol, Costa Blanca, Almería y Canarias. En Marbella, las 26 urbanizaciones registradas en 1969 había dado paso a 114 tres años después (Gaviria, 1974a).

${ }^{8}$ El gobierno civil de Málaga alude a las 57 urbanizaciones que surgen en la provincia en 1964, de las que sólo tres respetaban las leyes sobre construcción y distancia respecto al mar, y otras 27 se aprobaron a pesar de no cumplir los requisitos legales, y las 27 restantes simplemente se parcelaron y se vendieron a particulares sin ningún documento formal (Pack, 2009). 
pios ayuntamientos ${ }^{9}$, en abierto desafío a la Ley del Suelo de 1956 y a la Ley de Régimen Local de 1964.

La persistente demanda turística hacia las zonas litorales concentró a más de la mitad de los turistas en la costa mediterránea e islas Baleares y provocó la invasión anárquica de construcciones. Su volumen rompía el equilibrio ecológico de la costa, alteraba y degradaba el paisaje, creaban verdaderas murallas de cemento que aplastaban las playas y originaban superposiciones inadmisibles. Este urbanismo turístico poco respetuoso con la belleza natural de las playas, lo era también con los pueblos de pescadores (García Pablos, 1972). Y también lo denuncian los propios vecinos que sufren el desorden de los edificios y la destrucción de sus espacios naturales ${ }^{10}$. Serán muchos los analistas y técnicos que reclamen la necesidad de contemplar el entorno litoral como un verdadero patrimonio nacional, cuya utilización, protección, restauración y preservación debe gestionarse, de forma que se reconozcan y protejan los intereses públicos generales sobre los privados locales, preservando el carácter natural de la costa, protegiendo sus recursos y su ecología y manteniendo un criterio de reserva a largo plazo, más que de beneficio a corto por el uso intensivo del medio (Enríquez, 1972).

La oficialidad atribuye la situación a la presencia de operadores turísticos que «utilizan nuestra materia prima en bruto beneficiándose de su comercialización sin beneficio aparente para nuestro país» (Pack, 2009: 257). Pero este hecho y sus consecuencias territoriales las venían denunciando desde los años sesenta investigadores sociales, alarmados por la situación de dependencia y colonialismo turístico de las costas españolas debida a las facilidades dadas a la inversión extranjera en el sector inmobiliario (Díaz-Plaja, 1972; Gaviria 1974a, 1974b, 1975).

Este urbanismo de facto lo ratifica en 1972 el III Plan de Desarrollo al reconocer las grandes zonas turísticas donde se concentran los hoteles, urbaniza-

${ }^{9}$ El alcalde de Cullera otorga en 1963 a una empresa privada el derecho de construir, parcelar y vender grandes terrenos baldíos en las afueras de la localidad para segundas viviendas. En Mallorca, en 1964 la mitad de las urbanizaciones turísticas incumplían las normas legales (Pack, 2009).

${ }^{10}$ Los vecinos de la costa Brava denuncian la situación de Playa de Aro, desvarío del colosialismo, donde se están levantando moles descomunales, algunas de veinte plantas, como la llamada SunTower, «y todas en zona residencial, en primerísima línea, taponando las vistas al mar al inmenso número de viviendas que quedan detrás, y con destrucción previa del pinar que circunda la playa y que constituye su encanto y personalidad» (Pazos et al., 1965).

Estudios Geográficos, Vol. LXXVII, 281, pp. 391-414, julio-diciembre 2016 ISSN: 0014-1496, eISSN: 1988-8546, doi: 10.3989/estgeogr.201612 
ciones y apartamentos ${ }^{11}$. Pero el Plan sigue inflexible: «las prospecciones a largo plazo permiten afirmar que el incremento cuantitativo del turismo no decrecerá, lo que equivale a decir que se está aún lejos del punto de saturación. El turismo adolece, no obstante, de una excesiva concentración en el espacio, en el tiempo y en la motivación [...] El mantenimiento del ritmo de crecimiento de afluencia turística dependerá, cada vez menos, de la belleza del suelo y la bondad de su clima y, en mayor medida, de las inversiones que se vayan efectuando» (Ley 22/1972: 8266-8267).

De ahí las directrices en materia de política turística del III Plan: la promoción del turismo extranjero se dirigirá a conseguir, junto al aumento cuantitativo de la demanda, una clientela más seleccionada; se procurará obtener una mayor diversificación, espacial y temporal de las corrientes turísticas, y de las actividades que atraigan al turismo; la expansión de la oferta se acomodará a la demanda y se pondrán en explotación aquellas zonas nuevas que tengan las condiciones más aptas para su desarrollo turístico. Y las deficiencias que todavía existen se reconocen si se revisan las acciones que propone el Plan: un plan de saneamiento de aguas residuales en el litoral mediterráneo, Golfo de Cádiz, Baleares y Canarias; el ordenamiento de costas y playas; el control de los vertidos al mar de las aguas residuales; las extracciones de arena; la invasión del dominio público de la costa; impedir la nueva creación de centros turísticos sin las infraestructuras previas. Pero apenas se contemplan medidas concretas en los territorios deteriorados, más allá de que «Se proseguirá la ordenación y aprovechamiento del suelo, a fin de evitar la especulación, asegurar la defensa del paisaje y conseguir unas construcciones turísticas adecuadas al ambiente local» (Ley 22/1972: 8342).

Cuando dos años después la situación es ya irreversible se promulgan las Medidas de Ordenación de la Oferta Turística «para dar cumplimiento a la directriz de la política del III Plan de Desarrollo de acomodar la expansión de la

11 Las dieciocho grandes zonas turísticas consideradas, todas ubicadas en la costa, son: Costa Brava; Zona Norte del litoral barcelonés, comprendida entre Mongat y Malgrat; Costa mediterránea, desde Sitges a Cambrils y desde Vinaroz a Castellón; Núcleo turístico de los alrededores de Valencia; Costas levantinas de Sueca a Jávea, Calpe a Villajoyosa y Campello a Torrevieja; Zona del mar Menor; Costa almeriense, desde el Cabo de Gata a Adra; Litoral granadino, de Motril a Almuñecar; Zona Este de Málaga hasta Nerja; Costa de Torremolinos a Estepona; Litoral gaditano, entre Chiclana y Sanlúcar de Barrameda; Costa onubense, de Punta Umbría a Ayamonte; Costa vasca, desde Fuenterrabía a Algorta; Litoral de la provincia de Santander, desde Castro Urdiales a San Vicente de la Barquera; Costa coruñesa, entre Cabañas-Puentedeume y la capital; Rías Bajas gallegas, desde El Grove-La Toja hasta Bayona; Islas Baleares e Islas Canarias (Ley 22/1972: 8350). 
oferta cuantitativa, cualitativa y especialmente a la demanda y fomentar la explotación de las nuevas zonas que tengan las condiciones más aptas para su desarrollo turístico» (Decreto 2482/1974: 18685). Se retoma la «preocupación medioambiental» de adecuar el ritmo de las nuevas construcciones al de las infraestructuras del territorio y controlar que no degraden los elementos naturales que han actuado como factores de atracción turística. Este decreto viene a poner en evidencia el fracaso del modelo de política turística seguido hasta entonces.

En la II $^{\mathrm{a}}$ Asamblea Nacional de Turismo de 1975 las provincias ponen sobre la mesa los problemas existentes y sugieren acciones que deben acometerse (Asamblea, 1975). Resaltan la necesidad de una ordenación de las áreas turísticas para evitar el progresivo deterioro del medio ambiente, del potencial artístico-cultural y el agotamiento de los recursos turísticos por su explotación incontrolada. Reclaman la defensa de las playas y confirman que no se cumple la Ley de Costas de 1969. Reconocen que los centros aparecen totalmente aislados del contexto socioterritorial y sin la mayor preocupación sobre los efectos que producen en el terreno circundante, donde las casas individuales para vacaciones provocan situaciones de degradación, a veces definitiva, del patrimonio natural y del paisaje. Pero concluyen que las playas tienen todavía enormes posibilidades de desarrollo y que los puertos deportivos están insuficientemente promocionados y solicitan que los promotores puedan ganar terrenos al mar para compensar la inversión. No obstante, estas afirmaciones se contradicen con datos oficiales que demuestran que los puertos deportivos proliferaban por doquier ${ }^{12}$, y que eran muchos los agentes interesados, especialmente los promotores inmobiliarios ${ }^{13}$.

La Asamblea propondrá la reforma de la Ley de Centros y Zonas por quedar desfasada y ser poco atractiva. Reconoce que no se ha declarado ninguna zona y que se han denegado las de casi un centenar de centros por no cumplir

12 El informe del Grupo de Puertos de Barcelona y Tarragona en 1972 señala que son muchas las iniciativas para la construcción de puertos deportivos y no siempre su finalidad última es la de atender racionalmente una demanda potencial (Cantallops, 1977). El autor sostiene que a la especulación del suelo ha seguido la especulación del mar, pues los amarres en un puerto deportivo se consideran una inversión productiva, y algunas playas han sido gravemente afectadas no sólo por la privatización de un bien de la comunidad al servicio de unos pocos, sino por causar un daño irreparable al territorio.

${ }^{13}$ El director del puerto Banús en 1974 sostiene que el máximo beneficio económico que cabe esperar de un puerto deportivo es del 5 al 10\% del volumen de inversión y es evidente «que el beneficio debe buscarse uniendo al puerto una operación inmobiliaria, sea de revalorización de terrenos colindantes, sea de terrenos ganados al mar» (Herce, 1977: 53).

Estudios Geográficos, Vol. LXXVII, 281, pp. 391-414, julio-diciembre 2016 ISSN: 0014-1496, eISSN: 1988-8546, doi: 10.3989/estgeogr.201612 
los requisitos exigidos. En efecto, en 1974 los Centros declarados eran solamente 73, localizándose 52 en las costas, catorce en el interior y siete en zonas de montaña (Saín de Vicuña, 1974). Reiteran que la ordenación de las áreas turísticas se rija por la Ley de Centros y Zonas pero haciéndola coincidir con las exigencias de la nueva Ley del Suelo de 1975, que obliga a atender a los Planes Directores Territoriales de Coordinación y a los Planes Generales Municipales. Pero propone que sea preceptiva y vinculante la participación de Turismo en la redacción y aprobación de todos los planes, y si éstos afectaran a centros declarados, se respeten sus derechos a la hora de revisar su adaptación y se diese audiencia a los promotores en la tramitación del oportuno expediente ${ }^{14}$. También señala lo inoportuno de incorporar la obligatoriedad de ceder suelo a la Administración y solicita se reconsideren las condiciones para obtener la declaración de centro, rebajando tanto la capacidad mínima de plazas de alojamiento como la extensión superficial ${ }^{15}$.

Antes de que se proceda a la nueva organización territorial de España recogida en la Constitución de 1978, los estudios sobre la coyuntura del sector aconsejan proceder a la declaración de «Territorios de Preferente Uso Turístico», contemplada en el decreto de 1974 sobre Medidas de Ordenación de la Oferta Turística, y se dispone como delimitación más conveniente hacerlos coincidir con la extensión de los términos municipales en que se hallasen situados. El efecto es inmediato, pues en 1977 hay 73 municipios declarados de los que, salvo dos, se localizan en provincias litorales ${ }^{16}$.

\section{El DeSigual DeTERIORO DE LOS PAISAJES DEL INTERIOR}

El ministro Fraga para fomentar el turismo por el interior del país inaugura en 1963 la Exposición Nacional de Recursos Turísticos de España, certamen

${ }^{14}$ La Ley del Suelo de 1975 autorizaba al Gobierno a que en el plazo de un año, y a propuesta conjunta de los Ministerios de Información y Turismo y de la Vivienda, apruebe por decreto un texto Refundido de la Ley sobre Centros y Zonas que adapte sus normas urbanísticas a lo dispuesto en la Ley del Suelo de 1975.

15 En la Ley de Centros y Zonas la declaración de Centros sólo podría otorgarse cuando concurrieran en los mismos las siguientes condiciones: capacidad mínima de 500 plazas en alojamientos turísticos; una extensión superficial no inferior a diez hectáreas; contar con servicios adecuados a su capacidad de alojamiento.

${ }^{16}$ Las provincias y municipios declarados es la siguiente: Baleares (26), Gerona (11), Barcelona (9), Málaga (6), Alicante y Santa Cruz (3), Tarragona, Santander y Huesca (2) y Lérida, Castellón, Valencia, Almería, Granada, Huelva y Guipúzcoa (1) (Real Decreto 1077/1977). 
itinerante que habría de exhibirse en distintos países, a modo de compendio general de los atractivos turísticos de las distintas regiones, y pone en marcha el Folleto Provincial Unificado, de similar formato para todas las provincias. Asimismo, para estimular el interés de los territorios hacia el turismo y con vistas a su promoción dentro y fuera de España, crea el Registro de Denominaciones Geoturísticas como herramienta de difusión de los destinos (Orden, 31/03/1964). El registro servía para definir, fijar y delimitar lugares, pueblos, villas, ciudades, centros, zonas, costas, sierras, comarcas o regiones turísticas. La extensión superficial era variable y se tenían en cuenta valores geográficos o productivos. La inscripción la podrían solicitar autoridades locales, corporaciones, entidades públicas, así como personas naturales o jurídicas, y no implicaba titularidad, pues una vez inscrita definitivamente podía ser utilizada por todos aquellos que quisieran realizar propaganda turística en el ámbito territorial delimitado ${ }^{17}$.

También se pretende crear entre los españoles una conciencia turística y despertar su interés por los viajes, especialmente por el interior. Para ello Turismo editará en 1964 unos libritos con los títulos de «Español, conozca usted España», "Conozca usted su provincia» y "Conozca usted en mar». Y a través de su revista Noticiario Turístico divulgar los elementos históricos y monumentales repartidos por toda la geografía, donde se da cuenta de su localización exacta, descripción, accesibilidad, alojamientos disponibles en el entorno y, si lo hubiera, el sistema de visitas ${ }^{18}$. Asimismo se declaran las Fiestas de Interés Turístico, denominación honorífica concedida a más de 50 manifestaciones que pueden, además, optar a subvenciones ${ }^{19}$ (Orden, 30/09/1964).

Pero las pretensiones de las provincias reunidas en la Asamblea Nacional de Turismo de 1964 irán más allá. Aquellas que cuentan con sectores de montaña se decantan hacia el turismo de nieve, conscientes de que era el segmento

17 Se podían inscribir con nombres estrictamente geográficos, de fantasía, marcas comerciales o nombres de propiedades. La mayoría mezclaban lo geográfico con un eslogan que solía resaltar algún aspecto atrayente del lugar. Podían estar escritas en castellano, catalán, gallego o vascuence (Gómez Lozano, 2000, 2010).

${ }^{18}$ En varios números de la revista de 1964 se recogen 151 cuevas prehistóricas, 126 castillos y 394 monasterios (Noticiario Turístico, 1964).

${ }^{19}$ Entre las declaraciones se encuentran: la Semana Santa de Sevilla, Málaga y Zamora; el Corpus Christi de Toledo y Sitges; las Fiestas Lustrales de Santa Cruz de La Palma; el Misterio de Elche; San Jordi y N ${ }^{a} S^{a}$ de la Merced en Barcelona; El Pilar en Zaragoza; El Rocío en Huelva; las Fallas en Valencia; San Fermín en Pamplona; la Feria de Abril de Sevilla; la Vendimia de Jerez; las Hogueras de San Juan en Alicante; las Fiestas de invierno en Cádiz; Moros y cristianos en Alcoy; el descenso del Sella en Asturias, etc. (Herrera, 1999).

Estudios Geográficos, Vol. LXXVII, 281, pp. 391-414, julio-diciembre 2016 ISSN: 0014-1496, eISSN: 1988-8546, doi: 10.3989/estgeogr.201612 
turístico de mayor vitalidad detrás del costero y solicitan la promoción de 38 estaciones invernales, de las que sólo seis estaban en funcionamiento ${ }^{20}$. Los problemas más recurrentes giran en torno a la propiedad del suelo. Ven necesario establecer servidumbres para evitar que los propietarios vallen o tapien las fincas impidiendo su utilización durante la temporada de nieve. Recomiendan, cuando la propiedad sea pública, sustituir la fórmula de concesiones de superficie por una cesión de plena propiedad, condicionada a que transcurridos 20 años los terrenos no utilizados vuelvan a su anterior propietario. En cualquier supuesto será necesaria la declaración de interés de preferente uso turístico-deportivo, que primaría sobre otros tipos de explotación.

También solicitan que se concedan los beneficios del crédito turístico no sólo a los alojamientos sino al resto de las instalaciones, petición que no recogía la Ley de 1964 sobre concesión de teleféricos dictada unos meses antes por la Jefatura del Estado ${ }^{21}$.(Ley 4/1964). Reclaman sacar adelante los estudios de la Comisión Interministerial de Turismo sobre la Ordenación, Promoción y Desarrollo Turístico de Sierra Nevada y el Proyecto de Desarrollo Turístico del núcleo central de la Sierra de Guadarrama, y redactar un Plan de Estaciones Invernales, plan que no se hará esperar pues verá la luz en 1966 con el nombre de Plan de Promoción de Estaciones de Montaña o de Turismo de Nieve ${ }^{22}$ (Pellejero, 2004).

Pero el interés suscitado por las estaciones de montaña venía acompañado por ser punta de lanza de futuras promociones residenciales. Así lo publicita en 1967 una de las estaciones: «una vez creado el atractivo de invierno y existiendo rotundamente el de verano, contamos con los proyectos e inmediata puesta en marcha de nuestro complejo residencial» ${ }^{23}$. Y este afán urbanizador de la alta montaña podía llegar a no tener reparos en transgredir la protección que disfrutaban ciertos territorios con el fin de conseguir la declaración de

${ }^{20}$ En este momento seis estaciones estaban en funcionamiento (La Molina, Nuria, Baqueira, Navacerrada, Candanchú y Pajares), ocho tenían proyectos avanzados (Benasque, Sierra Nevada, Cotos, Formigal, Rasos de Peguera, Alto Campoo, Tossa de Das y Llesuy), once los tenían iniciados y trece carecían de ellos (Asamblea, 1964).

${ }^{21}$ La Ley establecía que en las instalaciones de interés turístico las competencias, atribuidas por ley a Obras Públicas, deberían ejercitarse de forma coordinada con Turismo que, a tal fin, debería ser oído en todos los casos de ejecución de dichas competencias.

22 En 1966 se inauguran medios mecánicos en las estaciones del Pirineo catalán de La Molina, Vaqueira y Llesuy (Molinero, 1966).

23 Se trata de la estación de alta montaña Espot Esquí, lindante con la zona periférica del Parque Nacional de Aigües Tortes y Lago de San Mauricio, promovida por la empresa Promoción de Urbanismo e Inversiones, S.A. (Historia de la estación de esquí, 2008). 
Centro de Interés Turístico ${ }^{24}$. Y fueron muchas las estaciones de montaña creadas, tal y como proponía el II Plan de Desarrollo de 1968. De las seis estaciones existentes en 1964 se pasa a 26 en 1974, localizadas en los principales sistemas montañosos: catorce en el Pirineo, cuatro en la Cantábrica, otras cuatro en el Sistema Central, tres en el Sistema Ibérico y una en el Penibético (Moreno, 2007).

Otros espacios que ofrecen las provincias como recursos a explotar son los Parques Nacionales y los Sitios Naturales de Interés Nacional. Existían hasta 1955 cinco Parques Nacionales declarados y su definición la establecía desde 1957 la Ley de Montes ${ }^{25}$. Pero el informe final de la asamblea sugiere no declarar más y propone una reorganización del espacio con miras a un aprovechamiento turístico, dividiendo cada parque en tres zonas aproximadamente concéntricas: una de reserva integral, otra de reglamentación especial y una tercera de protección, pudiendo esta última acoger paradores y albergues, y posibilitar en sus alrededores la práctica de la caza y pesca. Las solicitudes de Sitios Naturales de Interés Nacional fueron muchas, pero finalmente sólo se añadirán 22 nuevos a los diecisiete existentes. Aunque la definición de Sitio Natural la establecía Agricultura ${ }^{26}$ se aconseja que el Estado adquiera los enclaves de propiedad privada que contuvieran, se construyan caminos y hagan repoblaciones forestales, cinegéticas y piscícolas. Y también

${ }^{24}$ La empresa Promociones de Montaña, S.A. quiso promover una urbanización en la finca Valcotos de 268 hectáreas en parte ubicada en el Sitio de Interés Nacional de Peñalara, declarado desde 1930 y en pleno corazón de la sierra de Guadarrama. En 1973 COPLACO e ICONA rechazarán el proyecto. Pese a ello, el Consejo de Ministros aprobará en 1975 la declaración del Centro de Interés Turístico Nacional de Valcotos. Tras la polémica desatada por asociaciones ecologistas y vecinos de Rascafría, en 1977 el Consejo de Estado, tras consultas a los Ministerios de la Vivienda (COPLACO), Agricultura (ICONA), Obras Públicas, Gobernación y Educación Nacional, lo rechaza (Baviano, 1977) y (Pablos, 1978).

${ }^{25} \mathrm{La}$ Ley de 1957 los define como sitios o parajes excepcionalmente pintorescos, forestales o agrestes, en los que el Estado velará por hacer que se respete la belleza natural de su paisaje, la riqueza de su fauna y de su flora y las particularidades geológicas o hidrológicas, evitando todo acto de destrucción, deterioro o desfiguración. Su declaración la propone el Ministerio de Agricultura en cuyo Consejo está representado el Ministerio de Información y Turismo (Ley, 8/06/1957).

${ }^{26}$ El reglamento de la Ley de Montes previene que se podrán así calificar los parajes agrestes del territorio nacional, aun cuando su extensión sea reducida, que, sin reunir las condiciones necesarias para ser declarados Parques Nacionales, merezcan ser objeto de especial distinción por su belleza natural, lo pintoresco del lugar, la exuberancia y particularidades de la vegetación espontánea, las formas hidrológicas o la magnificencia del paisaje y las especiales características de su fauna, o de su capacidad para albergarla (Decreto 485/1962).

Estudios Geográficos, Vol. LXXVII, 281, pp. 391-414, julio-diciembre 2016 ISSN: 0014-1496, eISSN: 1988-8546, doi: 10.3989/estgeogr.201612 
se decide solicitar una Reserva Natural en el Coto de Doñana de las provincias de Huelva y Cádiz.

En paralelo, técnicos de distintos organismos de la administración reclamarán soluciones a los problemas que existen en torno a la ordenación y defensa de los recursos naturales. Vivienda los achaca a la falta de una normativa de conjunto que derivaba en problemas de competencias entre los organismos responsables de los recursos, e «implica el riesgo de que las inmediatas finalidades o ventajas del sector respectivo se impongan sobre las de carácter general y permanente que el paisaje y las bellezas naturales deben satisfacer» (Serrano, 1965: 31-32). Pero pasarán diez años hasta que se apruebe la Ley de Espacios Naturales Protegidos, con el fin de contribuir a la conservación de la naturaleza y a la mejor utilización con fines educativos, científicos, culturales, recreativos, turísticos o socioeconómicos, clasificándolos en cuatro categorías: Reserva Integral, Parque Nacional, Paraje Natural de Interés Nacional y Parque Nacional (Ley 15/1975).

La posibilidad del deporte como actividad turística también se asocia al turismo de interior. Hay provincias que proponen en 1964 sus embalses y pantanos para el deporte náutico. Pronto, en 1966, se decreta para su ordenación, determinando Obras Públicas, oído Turismo, las actividades recreativas compatibles (Decreto 2495/1966). Dos años después se aprueba una clasificación, de embalses según su posible aprovechamiento secundario recreativo: caza y pesca; baños y natación; navegación deportiva a remo y a vela; navegación deportiva a motor. Esta clasificación cumplirá la función de informar no sólo a los usuarios, sino también a los promotores de urbanizaciones que desearan instalarse en las cercanías de los embalses. De 1969 a 1973 se aprobaron 29 proyectos de ordenación de embalses y otros siete estaban en trámite (Urbistondo, 1973). También la asamblea ve conveniente fomentar la construcción de campos de golf privados y públicos próximos a los lugares de gran afluencia turística, solicitando la Federación Española de Golf su urgente construcción en Alicante, Granada, Murcia, Mallorca, Guipúzcoa, La Coruña y Pontevedra.

A la vista del aumento del tráfico por carretera, que los extranjeros prefieren las playas y que el turismo monumental languidece, las conclusiones de la asamblea recomiendan trabajar en el establecimiento de rutas turísticas, con el fin descubrir nuevos itinerarios que lo merezcan por su valor monumental, paisajístico, folklórico o deportivo. A las rutas existentes, conocidas desde los años cuarenta como Rutas Nacionales, propone añadir doce más, así como establecer una serie de itinerarios que partiendo de Madrid y de duración variable satisfagan distintos intereses, desde los histórico-artístico y 
culturales del interior, hasta los que se encuentran en escenarios alejados de montaña o de playa ${ }^{27}$, así como otros que se desarrollen utilizando las vías fluviales y embalses.

El interés en incrementar el turismo por el interior del país lo recoge el II Plan de Desarrollo de 1968 que se marca el objetivo de superar los 22 millones de turistas extranjeros y aumentar la demanda interna hasta los doce millones. Aconseja seguir prestando atención al turismo de sol y playa, al ser pocos los que llegan a España para admirar los monumentos o el arte, pero recomienda aumentar las posibilidades que ofrecen los ríos y embalses, las estaciones de invierno, los sitios termales y el turismo rural, especialmente con vistas al turismo nacional.

Para incrementar el turismo rural se había puesto en funcionamiento en 1967 el Programa de Vacaciones en Casas de Labranza, dirigido a fomentar y facilitar la participación de los agricultores en la utilización económica de sus recursos turísticos y proporcionar simultáneamente a amplios sectores de la población urbana una forma de turismo a costes muy razonables. Se trataba de animar a los propietarios de fincas en regiones del interior a convertir sus casas en alojamientos turísticos que promocionen nuevas zonas y, de paso, evitar el despoblamiento del campo. El programa estaba a cargo de Agricultura y de la Secretaría de Turismo, correspondiendo a esta última la edición anual de una guía que clasificase la oferta por provincias y municipios ${ }^{28}$.

En el mismo sentido de estimular el turismo por el interior, aunque ahora poniendo el énfasis en los recursos culturales, se crean los Premios Nacionales y Regionales de Turismo, aunque condicionados a la instalación de establecimientos turísticos: «El notable interés que en orden a los valores turísticos por una parte, las peculiares características arquitectónicas de las diversas regiones españolas, tan enlazadas al carácter y ambiente de las zonas en que aparecen de manifiesto, así como, por otra, la debida adecuación de las construcciones al paisaje circundante que constituyen su entorno, hacen aconseja-

27 Se proponen: Toledo de noche; Castillos; Isabelina; Renacimiento castellano; Santa Teresa; Mudéjar aragonés; Alarcón está entre peñas; Alpujarra; Batuecas; Maragatería; Colombina; del Miño; Picos de Europa; del Sol; Mar Menor.

${ }^{28}$ En 1967 sólo se ofrecían 384 casas ubicadas en 35 localidades repartidas entre dos provincias, y en 1975 se llegó a 8.134 casas en 459 localidades y 41 provincias (Carazo, 1978). Señala el autor que la oferta podría haber sido mayor, pues no se desarrolló una normativa específica que apoyase y ordenase esta actividad turística y el respaldo oficial fue mínimo. De ahí que el número de familias agrarias que practicaban actividades turísticas era muy superior a las que se acogían al programa.

Estudios Geográficos, Vol. LXXVII, 281, pp. 391-414, julio-diciembre 2016 ISSN: 0014-1496, eISSN: 1988-8546, doi: 10.3989/estgeogr.201612 
ble la creación de unos premios mediante los que se recompense la adaptación de las edificaciones con finalidades turísticas a tales elementos ambientales» (Orden, 3/03/1970: 5017). Para ello se divide el territorio en once zonas definidas por su carácter arquitectónico-ambiental ${ }^{29}$. Y ante la necesidad de un equipamiento turístico conjunto que afronte, de forma análoga y comparativa, la ordenación y puesta al día de las principales rutas turísticas se establecen ocho rutas por territorios que contaban con importantes recursos, tanto artístico-monumentales como histórico-culturales ${ }^{30}$ (Orden, 9/03/1971).

La política turística que emana de los presupuestos del III Plan de Desarrollo de 1972 insiste ahora en aumentar el turismo extranjero hacia el interior del país: «La imagen de España ante el extranjero, debería combinarse: nuestro país no sólo ofrece sol y playa, sino también la posibilidad de esquiar en invierno, de aprender arte y cultura españoles en las universidades, de descansar y recuperarse en los balnearios, de encontrar un ambiente adecuado para la celebración de congresos y un sinfín de posibilidades. La diversidad que ofrece el país en cultura, paisaje, clima, etc. no ha sabido aprovecharse plenamente hasta el momento presente» (Ley 22/1972: 8266) insistiendo en que el crecimiento de afluencia turística dependerá en gran medida de las inversiones privadas.

Pero ya se empiezan a levantar voces de arquitectos que alertan de la degradación de los paisajes del interior: «Hay que prestar especial atención no sólo a las áreas de los litorales y a las insulares, sino a zonas interiores del país, donde surgen instalaciones o conjuntos turísticos en paisajes de gran belleza, tanto en las zonas de montaña como en los entornos de los lagos, presas y embalses, en las áreas de influencia de nuestras grandes ciudades histórico-artísticas y en los pueblos pintorescos que cubren la geografía del país» (García Pablos, 1972: 81), recomendando que a la hora de promocionar el turismo en el interior se atienda a su aprovechamiento, pero también a la protección de su patrimonio, tanto natural como artístico y cultural.

Cuando en 1975 se celebra la II ${ }^{a}$ Asamblea Nacional de Turismo se aprecia una inclinación en promocionar el turismo cultural y cierta sensibilización

${ }^{29}$ Las zonas son: Galaico-Astur-Cántabro; Vasco-Navarra; Ibero-Aragonesa; Catalana; Castellano-Leonesa; Extremadura; Central; Levantina; Andaluza; Balear; Canarias. Se concedían tres premios anuales por zona, tanto a construcciones de nueva planta como a las adaptaciones de edificios antiguos con carácter o valor artístico propio. Los premios tenían carácter honorífico y consistían en una placa para colocar en la fachada y en un diploma para el arquitecto o promotor.

${ }^{30}$ Las rutas son: Camino de Santiago; del Quijote; del Arte Hispano-Musulmán; de los Conquistadores; del Arte Románico; del Gótico; de la Fe; Colombina. 
hacia sus paisajes. Así, a las doce provincias que solicitan ayudas para instalar nuevas estaciones de invierno, pues las costosas inversiones en infraestructuras que requieren difícilmente pueden ser afrontadas por los promotores ${ }^{31}$, se suman diecisiete que muestran interés en fomentar su patrimonio cultural. Ven necesario hacer inventarios que recojan los valores de carácter monumental, los conjuntos arquitectónicos y urbanísticos y los lugares naturales de interés singular, añadiendo también las costumbres y fiestas populares, la música y danzas, y las artesanías locales. Proponen determinar «áreas de interés turístico preferente» dentro de regiones naturales homogéneas, a modo de unidades territoriales que englobasen más de un núcleo urbano y sus entornos agrícolas cultivados o naturales, y que contengan elementos patrimoniales de interés. Y demandan la urgente aplicación de las medidas previstas en el decreto de 1974 sobre Medidas de Ordenación de la Oferta Turística para evitar la continuación de las tendencias actuales que estaban provocando en los territorios del interior el deterioro del medio ambiente, del potencial artísticocultural y el agotamiento de los recursos turísticos.

\section{CONCLUSIONES}

Tras revisar la política turística del periodo se puede concluir, en primer lugar, que en el interés por los paisajes naturales y culturales del país predominó su consideración económica como recurso que contribuyera a aumentar el número de turistas, sin que hubiese una preocupación paralela en controlar y evitar su deterioro. En segundo lugar que la política turística, recogida en un elevado número de disposiciones, derivó en un desigual tratamiento para el territorio, favoreciendo el desarrollo del sector en unos ámbitos más que en otros. En tercer lugar que la aplicación de la política turística determinó resultados diferentes en el paisaje: una acelerada degradación de los paisajes costeros y un más lento y desigual deterioro de los paisajes del interior. En cuarto lugar, y clave en este desenlace, fue el comportamiento de la iniciativa privada, más interesada por los espacios de mayor demanda turística extranjera, los más favorecidos por las medidas políticas, y apática a invertir en el resto del territorio, contemplado por la política turística como complemento y orientado fundamentalmente al turismo nacional.

\footnotetext{
${ }^{31}$ Las provincias que reclaman ayudas para nuevas estaciones de invierno son: Ávila; Barcelona; Gerona; Huesca; Lérida; Logroño; Navarra; Orense; Palencia; Soria; Teruel y Valladolid.
} 
BiBLIOGRAFÍA

I Asamblea Nacional de Turismo (1964): Madrid, Ministerio de Información y Turismo. II ${ }^{a}$ Asamblea Nacional de Turismo (1974): Madrid, Ministerio de Información y Turismo.

Arespacochaga, J. (1966): "La especulación del suelo en las zonas turísticas", Economía financiera Española, 13-14, pp. 39-50.

Barrado, D. y Galiana, L. (2006): "Ideas y modelos de planificación territorial en los orígenes del turismo de masas español. La Ley de Centros y Zonas de Interés Turístico Nacional frente a la Ley del Suelo", Estudios Turísticos, 167, pp. 7-36.

Baviano, J. M. (1977): "La urbanización de Cotos, afectada por diferentes leyes del suelo", El País, 6-9-1977.

Bosch Aymerich, J. M. (1966): "Planeamiento creativo de suelo y promoción turística", en Desarrollo de Zonas Turísticas, Madrid, Instituto de Estudios Turísticos, pp. 9-23.

Calderón Calderón, B. (2001): "Entre la hipertrofia normativa y la des-ordenación del territorio: una aproximación a los fundamentos de la ordenación del espacio turístico en España”, Terra Nueva Etapa, XVII/26, pp. 11-41.

Cantallops, L. (1977): "La actividad recreativa y la costa de Cataluña", Ciudad y Territorio, 3, pp. 41-48.

Carazo, L. (1978): El turismo rural como recurso de la población agraria, http://www.magrana.gob.es/ministerio/pags/biblioteca/revistas/pdf (Fecha de consulta: $10 / 6 / 2014)$.

Díaz Plaja, G. (1972): El turismo, ¿un falso “boom?”. Introducción a la problemática socioeconómica del turismo en Baleares, Madrid, Edicusa, Cuadernos para el Diálogo. Colección Los Suplementos.

Enríquez Argós, F. (1972): "Las infraestructuras turísticas e industriales y su incidencia en el equilibrio físico y ecológico de la costa. Posibilidades de coexistencia", en Congreso de Ecología y Turismo del mediterráneo Occidental, Madrid, pp. 86-95.

García Pablos, R. (1972): "La ecología del medio urbano turístico. Concepto del medio urbano con especial referencia a la costa del mediterráneo. Integración de la arquitectura en el paisaje", en Congreso de Ecología y Turismo del mediterráneo Occidental, pp. 71-85.

Gaviria, M. (1974a): España a Go-Go. Turismo chárter y neocolonialismo del espacio, Madrid, Turner.

Gaviria, M. (1974b): "La producción neocolonialista del espacio", Revista de Sociología, 3, pp. 201-217.

Gaviria, M. (1975): El escándalo "court line” (Bancarrota del turismo español), Madrid, Edicusa, Cuadernos para el Diálogo. Colección Los Suplementos.

Gómez Lozano, M. C. (2000): "La denominación geoturística como herramienta estratégica de la promoción de los destinos turísticos en España. Consideraciones sobre su régimen jurídico", Revista de derecho mercantil, 236, pp. 695-716. 
Gómez Lozano, M. C. (2010): "Calidad y distintivos turísticos en la Ley de Turismo de Galicia", Revista de Derecho UNED, 6, pp. 537-541.

González Berenguer, J. L. (1969): Teoría y práctica del planeamiento urbanístico, Madrid, Escuela Nacional de Administración Pública.

Herce Vallejo, M. (1977): "La costa un recurso natural en proceso de deterioro", Ciudad y Territorio, 3, pp. 49-58.

Herrera y Esteban, L. (1999): "La expansión, 1962-1972”, en F. Bayón, 50 años de turismo español: un análisis histórico y estructural, Madrid, Centro de Estudios Ramón Areces, pp. 71-104.

Historia de la estación de esqui de Espot Esquí (2008): http://www.nevasport.com/reportaje/art/32195 (Fecha de consulta: 2/6/2014).

Jaimez, I. (2004): Políticas públicas y turismo, Sevilla, Junta de Andalucía.

La España que usted no conoce (1965): Madrid, Dirección General de Turismo.

Molinero, C. (1966): "La región de norte a sur. Estaciones invernales", La Vanguardia, 21-12-1966.

Moreno Garrido, A. (2007): Historia del turismo, Madrid, Síntesis.

Noticiario Turístico (1964): $\mathrm{n}^{\circ}$ 63, 65, 68 y 70.

Pablos, J. M. de (1978): "El Plan de Cotos, infracción urbanística", ABC, 1-7-1978.

Pack, S. (2009): La invasión pacífica. Los turistas y la España de Franco, Madrid, Turner.

Pazos, C. et al. (1965): "Anarquía en las construcciones de la Costa Brava”, ABC, 8-91965.

Pellejero, C. (2004): "Organización administrativa e intervención del Estado en el sector turístico: 1951-1977”, Estudios Turísticos, 163-164, pp. 81-97.

Sainz de Vicuña, M. (1974): "Centros y Zonas de Interés Turístico Nacional”, en Tecnología de las infraestructuras turísticas, Madrid, Colegio Oficial de ICCP, pp. 175-194.

Sánchez Sánchez, E. (2001): "El auge del turismo europeo en la España de los años sesenta", Albor, CLXX/669, pp. 201-224.

Sanz Pareja, E. (1966): "Problemas en relación con el litoral y el desarrollo de zonas", en Desarrollo de Zonas Turísticas, Madrid, Instituto de Estudios Turísticos, pp. 5366.

Serrano Guirado, E. (1965): Planificación territorial y planificaciones sectoriales. Consideración especial del sector turístico, Madrid, Ministerio de la Vivienda.

Serrano Guirado, E. (1966): "Planificación territorial y planificaciones sectoriales", en Desarrollo de Zonas Turísticas, Madrid, Instituto de Estudios Turísticos.

Subsecretaría de Turismo (1964): España para usted, Madrid, Subsecretaría de Turismo.

Urbistondo, R. (1973): "El aprovechamiento recreativo de los embalses españoles", Revista de Obras Públicas, Junio, pp. 561-580.

Vallejo Pousada, R. (2014): "De país turístico rezagado a potencia turística. El turismo en la España de Franco", Asociación Española de Historia Económica, documentos de trabajo, $\mathrm{n}^{\circ} 1408$.

Estudios Geográficos, Vol. LXXVII, 281, pp. 391-414, julio-diciembre 2016

ISSN: 0014-1496, eISSN: 1988-8546, doi: 10.3989/estgeogr.201612 
Velasco, M. (2004): La política turística. Gobierno y administración turística en España (1952-2004), Valencia, Tiran lo Blanc.

Velasco, M. (2008): "Evolución de los problemas del turismo español. La Administración General del Estado como analista y los Planes públicos como indicadores (1952-2006)", Papers de Turismo, 43-44, pp. 7-31.

Zaragoza, P. (1999): “Actuaciones urbanísticas. 1972-1980”, en F. Bayón, 50 años de turismo español: un análisis histórico y estructural, Madrid, Centro de Estudios Ramón Areces, pp. 125-132.

\section{LEGISLACIÓN}

Decreto 485/1962, de 22 de febrero, por el que se aprueba el Reglamento de Montes, BOE $\mathrm{n}^{\mathrm{o}} 61,12-3-1962$.

Decreto 4297/1964, de 23 de diciembre, por el que se aprueba el Reglamento de la Ley sobre centros y zonas de interés turístico nacional, BOE nº 14, 16-1-1965.

Decreto 2495/1966, de 10 de septiembre, (Ministerio de Obras Públicas), Embalses, Ordenación, BOE $\mathrm{n}^{\circ} 242,10-10-1966$.

Decreto 3787/1970, de 19 de diciembre, de requisitos mínimos de infraestructuras y dotaciones en Zonas y Centros de Interés Turístico Nacional, BOE, $\mathrm{n}^{\circ}$ 15, 18-1-1971.

Decreto 2482/1974, de 9 de agosto, sobre Medidas de ordenación de la oferta turística, BOE, no 217, 10-9-1974.

Ley 12/05/1956 sobre régimen del suelo y ordenación urbana, BOE, $\mathrm{n}^{\circ} 135,14-5-1956$.

Ley 8/06/1957, sobre nueva ley de Montes, BOE, $\mathrm{n}^{\circ}$ 154, 10-6-1957.

Ley 48/1963, de 8 de julio, sobre competencias en materia turística, BOE, $\mathrm{n}^{\circ} 164,10-7-$ 1963.

Ley 197/1963, de 28 de diciembre, sobre "Centros y Zonas de Interés Turístico Nacional", BOE, $n^{\circ} 313,31-12-1963$ y BOE no $114,12-5-1972$,

Ley 4/1964, de 29 de abril sobre concesión de teleféricos, BOE, nº 107, 4-5-1964.

Ley 55/1969, de 26 de abril, sobre puertos deportivos, BOE nº 521, 20-4-1969.

Ley 28/1969, de 26 de abril sobre costas, BOE, no 101, 28-4-1969.

Ley 22/1972, de 10 de mayo, de aprobación del III Plan de Desarrollo Económico y Social, BOE ${ }^{\circ} 113,11-5-1972$.

Ley 15/1975, de 2 de mayo, de espacios protegidos, BOE, no 107, 5-5-1975.

Orden 31/03/1964 por la que se crea en la Subsecretaría de Turismo el Registro de Denominaciones Geoturísticas, BOE no 87, 10-4-1964.

Orden 30/09/1964 por la que se crea la denominación honorífica de "Fiesta de Interés Turístico”, BOE, no 251, 19-10-1964.

Orden 3/03/1970 por el que se crean los Premios Nacionales y Regionales de Turismo, BOE $n^{\circ} 77,31-3-1970$.

Orden 9/03/1971 sobre determinación de Zonas y Rutas Turísticas, BOE, nº 66, 18-41971. 